TAO, Vol. 16, No. 3, 595-620, August 2005

\title{
Sandbox Experiments of Plate Convergence - Scale Effect and Associated Mechanisms
}

\author{
Ming-Lang Lin ${ }^{1}$, Chia-Yu Lư ${ }^{2}$, Kuo-Jen Chang ${ }^{2}$, Fu-Shu Jeng ${ }^{1, *}$ and Chung-Jeng Lee ${ }^{3}$
}

(Manuscript received 2 December 2004, in final form 6 July 2005)

\begin{abstract}
When using a sandbox to simulate tectonic activities, it is essential to thoroughly understand scale effect and its consequence so as to ensure an adequate model with representative simulation results. This paper investigates the topography, faulting lineaments, and internal structures of different scales associated with the simulation of plate convergence using sandbox modeling, based on three major test series. In the first test series, plate convergence is performed using simple models with flat bases to investigate fundamental behavior and observe the scale effect. The scales of sandbox models are altered either by varying the thickness of sand or by applying centrifugal conditions. The models have a relative depth scale of $1: 2: 20: 40$.In the second test series, the scale effects of a sandbox modeling given more realistic conditions are studied, i.e., models with underlain basement highs based on the configuration of western Taiwan. In the third test series, the impact of rougher base friction, and the effects of compaction are investigated to identify possible factors related to scale effect. Based on the observed scale effect, the possible factors accounting for scale effects are also discussed in this paper.

Just like most sands, the sand tested is characterized by two phenomena: (1) its internal frictional angle increases from $34^{\circ}$ to $41^{\circ}$ under greater degrees of compaction, with a relative density ranging from 55 to $90 \%$; and (2) it possesses nonlinear constitutive behavior, whereby the deformational modulus increases upon greater confining stress. Such behavior inherently accounts for scale effect in the way that the embedded stress of sand is
\end{abstract}

\footnotetext{
1 Department of Civil Engineering, National Taiwan University, Taipei, Taiwan, ROC

2 Institute of Geoscience, National Taiwan University, Taipei, Taiwan, ROC

${ }^{3}$ Department of Civil Engineering, National Central University, Chung-Li, Taiwan, ROC

* Corresponding author address: Prof. Fu-Shu Jeng, Department of Civil Engineering, National Taiwan University, Taipei, Taiwan, ROC; E-mail: fsjeng@ntu.edu.tw
} 
proportional to its depth; however, the frictional angle and the stiffness of sand cannot be retained constant.

Results obtained from the first test series indicate that models with greater depth scale tend to have less deformation concentration near the backstop, quicker thrust faulting and longer fault propagation distances. Meanwhile, internal structures of models with greater depth scales, characterized by more pop-up structures, differ from those of small-scale models. Based on the critical wedge theory, the smaller slope angle yielded under a greater depth scale indicates stronger material strength, which results from greater confining stress or compaction. Moreover, the hardening, or increased stiffness of sand may facilitate forward propagation of convergence stress thereby contributing to the occurrence of scale effect.

For the second test series, the yielding of three major fault groups, and curved faults is consistent for different scales and scale effect seems to be diminished. Nevertheless, when looking at internal structures, scale effect does exist. Here, more pop-up structures were yielded under a greater depth scale. This indicates that model geometry may suppress some part of scale effect.

The third test series shows that the deformation pattern of models with compacted sand or with smoother bases resembles that of a greater scale model. Correspondingly, sand compaction as a factor is highlighted among those possible factors.

(Key words: Plate convergence, Fold-and-thrust structures, Sandbox simulation, Depth scale effect, Centrifuge.)

\section{INTRODUCTION}

Sandbox experiments provide an effective means of simulating tectonic processes such as divergence or convergence of plates by stretching or compressing sand in a sandbox model (e.g., Davis et al. 1983; Dahlen et al. 1984; Malavieille 1984; Mulugeta 1988a, b, 2002; Bar and Dahlen 1989; Dahlen and Barr 1989; Dahlen 1990; Colletta et al. 1991; Liu et al. 1991; Lallemand et al. 1992; Willett 1992; Willett et al. 1993; Byrne et al. 1993; Calassou et al. 1993; Sassi et al. 1993; Lu and Malavieille 1994; Lallemand et al. 1994; Lu et al. 1995; Koyi 1995; Gutscher et al. 1996, 1998a, b; Mugnier et al. 1997; Wand and Davis 1996; Storti et al. 1997; Lu et al. 1998; Bonini et al. 2000; Wang and Hung 2002; Costa and Vendeville 2002; Lu et al. 2002; Mouthereau et al. 2002; Koyi and Vendeville 2003; Maillard et al. 2003; CouzensSchultz et al. 2003). The deformational process and resulting structures observed in sandbox modeling not only provide further insight into actual tectonic activities, but also facilitate an interpretation into the nature of the associated mechanism. For instance, $\mathrm{Lu}$ and Malavieille (1994) performed 3-D sandbox modelling experiments to illustrate the evolution of the Taiwan thrust wedge during oblique convergence. The major result obtained from this model was 
the development of an asymmetrical thrust wedge with different tectonic domains, comprising different combinations of compression, rotation and extension, resulting in a local partitioning between thrusting and strike-slip faulting.

Lu et al. (1998) performed a series of sandbox experiments, and discussed the impact of the basement high on the structures and kinematics of the western Taiwan thrust wedge. They found that most of the foreland structures were strongly influenced by the shape of the backstop and structure highs. Lu et al. (2002) discussed how the shape of the basement controlled the foreland fold-and-thrust structures, which in turn induced the out-of-sequence thrusting and tectonic features of the 1999 Chi-Chi Taiwan earthquake.

Typically the size of sandbox models used to simulate plate convergence is within a few meters or centimeters, whereas the simulated regions normally range from several kilometers to several tens of kilometers requiring a scale reduction of 1/100000 or even smaller. Models scaled on such a basis must consider scale factor issues to ensure they reflect actual geological processes well.

Factors influencing model simulation may include the following:

1. Geometric configuration of the sandbox model and backstop to reflect actual geological conditions;

2. Boundary conditions - the boundaries of a sandbox, including the base and the lateral confinement, exhibit frictional effects that may substantially affect model simulation. A proper model should minimize the influence of lateral boundary friction conditions on the experimental results, while simulating the basal friction as realistically as possible;

3. Property of model material - rheological similarity must be satisfied. For instance, the model material should possess similar deformational and fracturing behavior to correspond to the actual behavior of stratum under geologic processes;

4. Control of material properties - Rheological similarity must be fulfilled such that experimental results obtained from various tests can be analyzed and compared with nature. For instance, factors such as strength, grain size distribution, relative density and presence of water influencing the mechanical properties of sand must be given consideration;

5. Chosen scale - selection of a proper model scale is important to ensure a representative simulation as long as scale effect exists.

To achieve a proper model simulation, Mulugeta (1988a) proposed the following relationship concerning dynamic similarity:

$$
\frac{\rho_{\mathrm{p}} \mathrm{g}_{\mathrm{p}} 1_{\mathrm{p}}}{\tau_{\mathrm{p}}}=\frac{\rho_{\mathrm{m}} \mathrm{g}_{\mathrm{m}} I_{\mathrm{m}}}{\tau_{\mathrm{m}}}
$$

Where $\tau=$ cohesive strength of stratum; $\rho=$ density; $\mathrm{g}=$ magnitude of gravity (above symbols are different from Mulugeta, 1988a); $1=$ length scale; and the subscripts, $p$ and $m$, represent the parameters for the prototype and for the model, respectively.

If uniaxial strength of rock is $10 \mathrm{MPa}$ with a density of $2.4 \mathrm{gm} \mathrm{cm}^{-3}$ and the $I_{\mathrm{p}} / I_{\mathrm{m}}=10^{5}$, the cohesive strength of model material should not exceed $0.13 \mathrm{kPa} \approx 0$. In light of this concern, a material with zero or negligible strength is preferred. Consequently, sand is frequently cho- 
sen as a model material since it is characterized by a negligible cohesive strength.

However, the properties of sand, which depend on the level of consolidation stress, may inherently impact the outcome of an experiment. The stress-dependent properties of sand include: stiffness, friction angle and relative density, etc. Since model depth scale pertinently determines corresponding levels of consolidation stress in model simulation, the properties of sand vary accordingly with model scales. Therefore, analyses concerning scale effect must be made while using sand as a model material. Thus, in this paper, experiments that simulate sand deformation of different depth scales are presented.

\section{TESTING CONCEPTS AND SETUP}

Three test series are performed to evaluate scale effect in sandbox simulations of plate convergence. In a first series of tests, a simplified model with a flat base (Figs. 1a, b) is adopted to explore the fundamental behavior of plate convergence. In the second series of tests, a more realistic configuration, i.e., a model with an elevated base representing a basement high, is adopted to simulate the plate convergence in front of a basement high (Fig. 1c). The geometrical configuration of the basement high is representative of the Peikang Basement High and Kuanyin Basement High in western Taiwan (Lu et al. 1998; Mouthereau et al. 2002) (Fig. 2). In the third series, the influence of the factors associated with scale effect, including basal friction and degree of compaction, is evaluated through experiments described here.

Two approaches can be employed to construct models of different scales: either construct a model with the same geometrical configuration but of different sizes, or perform experiments under normal and centrifugal conditions with the same model. While the same model is tested under various centrifugal conditions, an identical ratio of sand particle sizes to the model size is maintained; consequently, the effect of particle size can be isolated. However, the prior approach should be chosen, as far as the impact of particle size to scale effect is concerned. In this research, both approaches are adopted. The length scale of a model is altered either by increasing the thickness of sand (from $2 \mathrm{~cm}$ to $4 \mathrm{~cm}$ ) or by increasing the gravity magnitudes (from $1 \mathrm{~g}$ to $20 \mathrm{~g}$ ). Therefore, the relative scale of the models is $1: 2: 20: 40$.

Herein, the experiments under $20 \mathrm{~g}$ conditions are performed in a centrifuge with the major specifications listed in Table 1 . The centrifuge used can provide a maximum acceleration of $200 \mathrm{~g}$, here only a $20 \mathrm{~g}$ condition is tested, in accordance with a feasible sandbox size given laboratory conditions.

Limited by the available space in a centrifuge frame, the sandbox has a dimension of 60 (length) $\times 40$ (width) $\times 35$ (height) $\mathrm{cm}$, which is bigger than the sandboxes used in a previous centrifuge study $(20 \times 18 \times 10 \mathrm{~cm}$; Mulugeta 1988b). Consequently, this sandbox further reduces the influence of friction induced by the lateral boundaries. For the model with a basement high, the slope angle of the basement high is increased to 10 20 degrees from the actual angle of 5 10 degrees in accordance with the limitation on sandbox size and meanwhile, to magnify the influence of an ascending basement slope.

Lu and Malavieille (1994) used a corner shaped incline backstop as an analog of the plate configuration of the Taiwan Orogeny. Owing to the spatial limitation imposed by centrifuge 
(a)
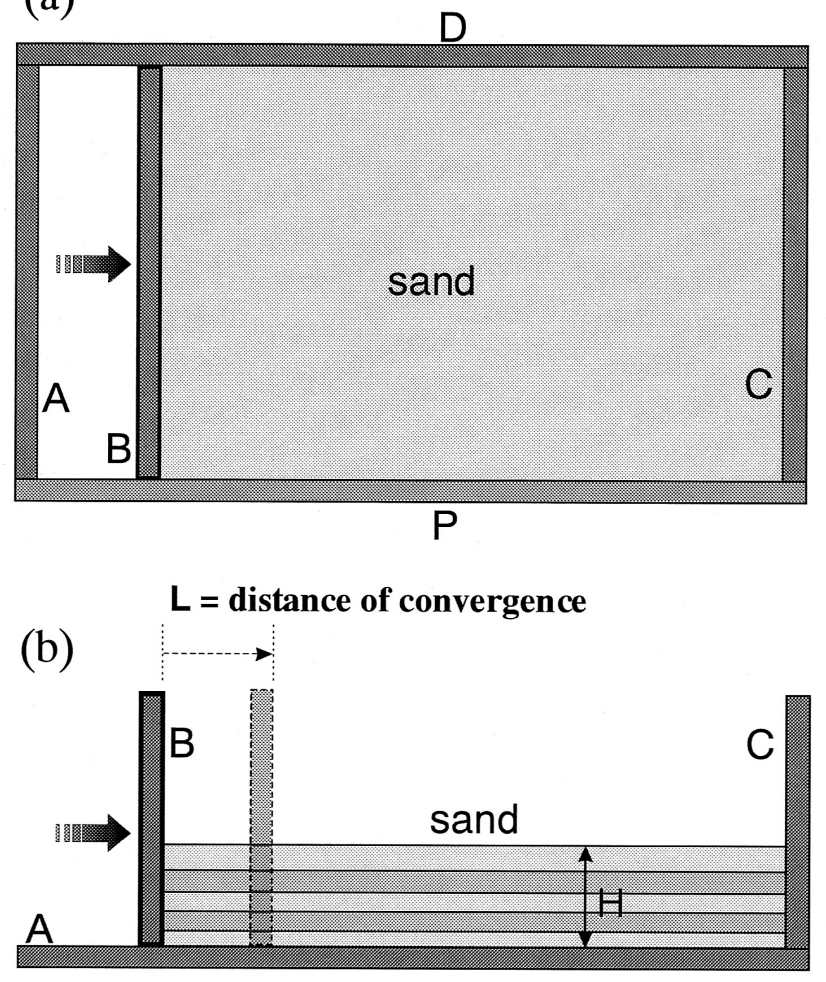

(c)

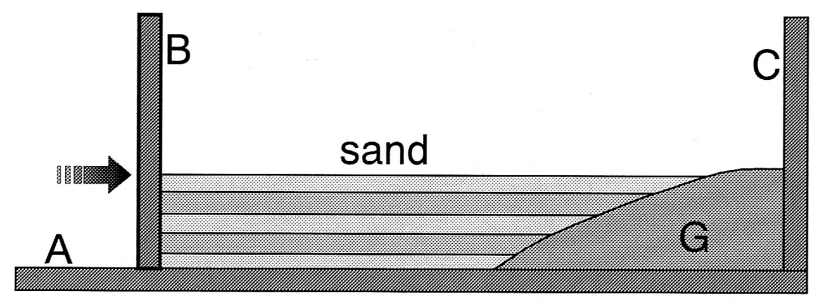

Fig. 1. Schematic setup of sandbox model for simulating plate convergence (not to scale). The arrow indicates direction of convergence. $\mathrm{B}=$ backstop (aluminum); $\mathrm{P}=$ Plexiglas; $\mathrm{G}=$ gypsum (basement high). $\mathrm{D}=$ boundary of sandbox, $\mathrm{L}=$ distance of convergence; $\mathrm{H}=$ depth of the soil.
(a) Plan view of sandbox
(b) Side view of sandbox - flat base model
(c) Side view of sandbox - elevated base model 


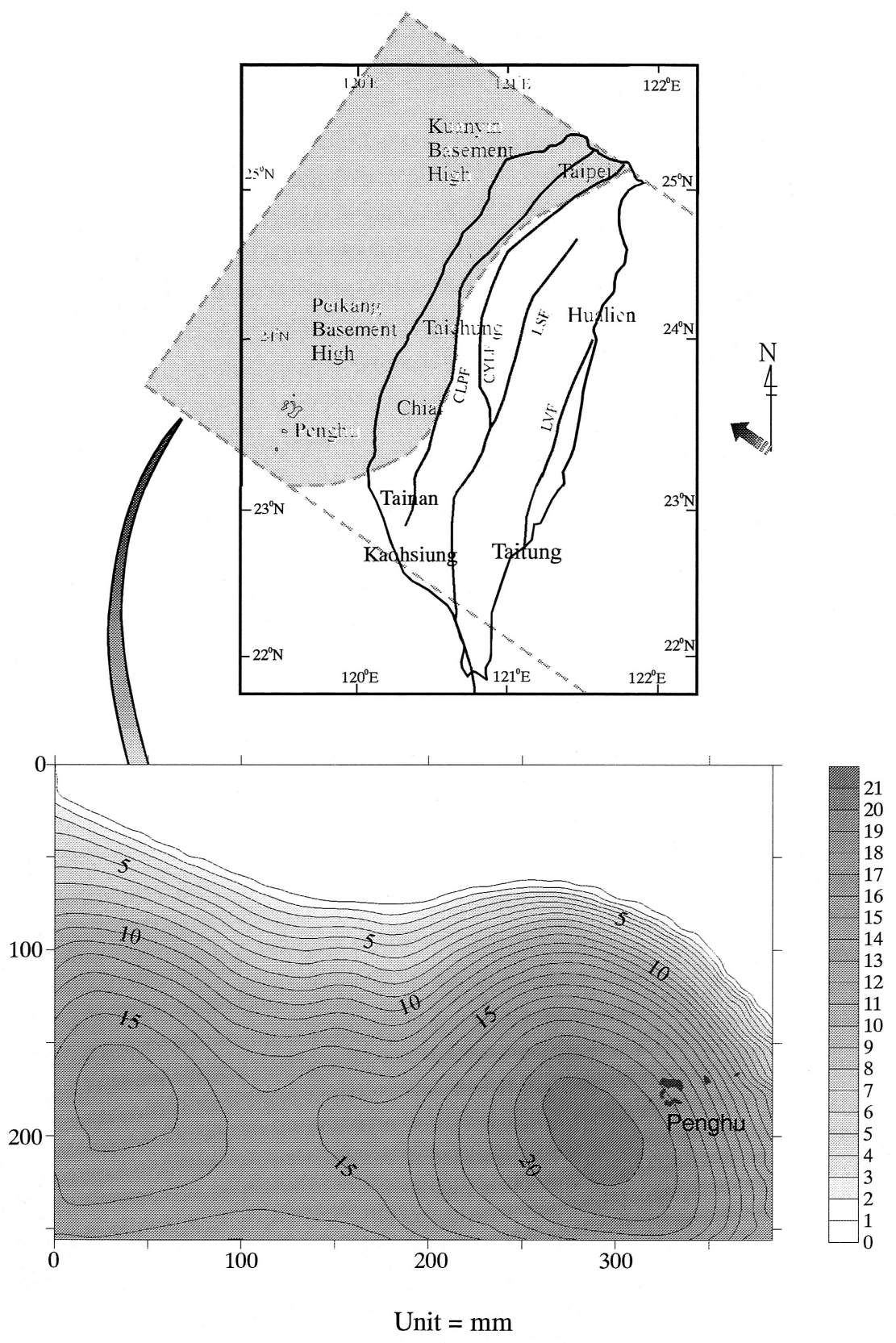

Fig. 2. Configuration of basement high (modified after Lu et al. 1998 and Mouthereau et al. 2002), indicate the elevation of the basement high. CLPF: Chelungpu Fault, CYLF: Chenyulanchi Fault, LSF: Lishan Fault, LVF: Longitudinal Valley Fault. 
Table 1. Major specifications of centrifuge facility.

\begin{tabular}{|l|l|}
\hline Maximum centrifugal acceleration & $200 \mathrm{~g}$ \\
\hline Capacity & $200 \mathrm{~g} \times$ ton \\
\hline $\begin{array}{l}\text { Dimension of maximum mountable } \\
\text { container }\end{array}$ & $1 \mathrm{~m} \times 0.8 \mathrm{~m}$ in plan, $0.8 \mathrm{~m}$ in height \\
\hline Type of centrifuge & Beam \\
\hline Effective radius & $3 \mathrm{~m}$ \\
\hline Location of centrifuge & National Central Lniversity, Chungli, Taiwan. \\
\hline
\end{tabular}

testing, a vertical backstop is used instead of an inclined indenter.

Convergence is induced by pushing forward the rear wall of the sandbox, at a rate of $4 \mathrm{~mm} \mathrm{~min}^{-1}$ based on the experimental technique developed by Lu and Malavieille (1994), and hence squeezes the sand pack.

After several preliminary tests relating to the model size and other related factors as well as verify the replication of experiments, this work presents nine final tests with testing conditions summarized in Table 2.

The sand adopted is sub-rounded and composed primarily of quartz (more than $90 \%$ by weight) containing also a minor portion of feldspar and mica. Most of the sand grains have sizes ranging from $0.425 \mathrm{~mm}$ (\#40 sieve) to $0.15 \mathrm{~mm}$ (\#100 sieve) with a uniformity index $\left(\mathrm{C}_{\mathrm{u}}\right)=1.56$ and a coefficient of gradation $\left(\mathrm{C}_{\mathrm{c}}\right)=1.0$. The maximum and minimum densities are $1.667 \mathrm{gm} \mathrm{cm}^{-3}$ and $1.429 \mathrm{gm} \mathrm{cm}^{-3}$, respectively. The relative density of the sand prepared for sandbox testing ranges from 55 to $90 \%$.

The shear strength and the variation of frictional angle with relative density of the experimental sand are shown in Figs. 3a, b, respectively. Similar to most sands, the adopted sand under various stress levels is characterized with an almost linear failure envelope, which has a cohesion intercept close to zero.

The friction angle $(\phi)$ of the sand ranges from $34^{\circ}$ to $41^{\circ}$ for the relative density ranging from 55 to $90 \%$. Namely, the sand tends to have a minor increase in frictional angle when it is more densely packed (or has higher relative density).

However, a non-linear relationship between the applied stress and the axial strain exists as shown in Fig. 4. The slope of the curve represents the stiffness of sand (constrained modulus). According to Fig. 4b, a 50\% increase in the applied strain (from 1 to 1.5\%) significantly increases the constrained modulus almost two-fold (from $110 \mathrm{MPa}$ to $200 \mathrm{MPa}$ ).

Restated, sand exhibits substantial stress dependent behavior. This behavior indicates that the sand is relatively stiffer when it is deformed under a greater scale. Such behavior, which enables the sand to become stiffer under greater depth scales, inherently may facilitate the propagation of convergence stress and render scale effect. 
Table 2. Summary of tests and associated testing conditions.

\begin{tabular}{|c|c|c|c|c|c|c|c|}
\hline Test \# & $\begin{array}{c}\text { Geometry of } \\
\text { base }\end{array}$ & $\begin{array}{c}\mathrm{N} \\
(\mathrm{g})\end{array}$ & $\begin{array}{c}\mathrm{H}^{*} \\
(\mathrm{~cm})\end{array}$ & $\begin{array}{c}\mathrm{W} \\
(\mathrm{cm})\end{array}$ & $\begin{array}{c}\mathrm{L}_{\mathrm{i}} \\
(\mathrm{cm})\end{array}$ & $\begin{array}{c}\mathrm{L}_{\mathrm{f}} \\
(\mathrm{cm})\end{array}$ & Other conditions \\
\hline 1 & flat & 1 & 2 & 40 & 60 & 40.0 & $\begin{array}{c}\text { Normal base friction } \\
\text { Sand not compacted }\end{array}$ \\
\hline 2 & flat & 20 & 2 & 40 & 60 & 40.0 & $\begin{array}{c}\text { Normal base friction } \\
\text { Sand not compacted }\end{array}$ \\
\hline 3 & flat & 1 & 4 & 40 & 60 & 40.0 & $\begin{array}{c}\text { Normal base friction } \\
\text { Sand not compacted }\end{array}$ \\
\hline 4 & flat & 20 & 4 & 40 & 60 & 45.7 & $\begin{array}{c}\text { Normal base friction } \\
\text { Sand not compacted }\end{array}$ \\
\hline 5 & elevated & 1 & $0 \sim 2$ & 40 & 45 & 40.5 & $\begin{array}{c}\text { Normal base friction } \\
\text { Sand not compacted }\end{array}$ \\
\hline 6 & elevated & 20 & $0 \sim 2$ & 40 & 45 & 41.5 & $\begin{array}{c}\text { Normal base friction } \\
\text { Sand not compacted }\end{array}$ \\
\hline 7 & flat & 1 & 4 & 27 & 56 & 29.0 & $\begin{array}{c}\text { Normal base friction } \\
\text { Sand not compacted }\end{array}$ \\
\hline 8 & flat & 1 & 4 & 27 & 56 & 33.0 & $\begin{array}{c}\text { Rough base } \\
\text { Sand not compacted }\end{array}$ \\
\hline 9 & flat & 1 & 4 & 27 & 56 & 24.0 & $\begin{array}{c}\text { Normal base friction } \\
\text { Compacted sand }\end{array}$ \\
\hline
\end{tabular}

Symbols:

$\mathrm{N}$ = magnitude of gravity; $\mathrm{H}=$ thickness of sand for flat base or maximum thickness of sand for elevated base; $\mathrm{W}=$ width of sandbox; $\mathrm{L}_{\mathrm{i}}=$ Initial length of sand layer; $\mathrm{L}_{\mathrm{f}}=$ Final length of sand layer.

\section{TEST RESULTS - FLAT BASE MODEL}

\subsection{Generation of Thrust Faults}

Figure 5a illustrates typical deformation of a sand model above a flat base. As each of the experimental results is compared later in this work, the scale and orientation of each experimental section must correspond to each other. For this purpose, the photo was scanned into a computer and carefully sketched (Fig. 5b).

Thrust faults and pop-ups were formed as the backstop was pushed from left to right as shown in Fig. 6 (Test No. 3 in Table 2). A pop-up structure initially formed near the backstop. Upon subsequent squeezing, more thrust faults formed and propagated towards the far end of the model. This fault propagation resulted in a sequence of imbricate thrust slices from the backstop to the other end as indicated by the numbers in Fig. 6 .

A pop-up structure was bounded by a set of fore-thrust and back-thrust faults with similar inclination while initiated. With increasing convergence, the pop-up wedge underwent a for- 
(a)

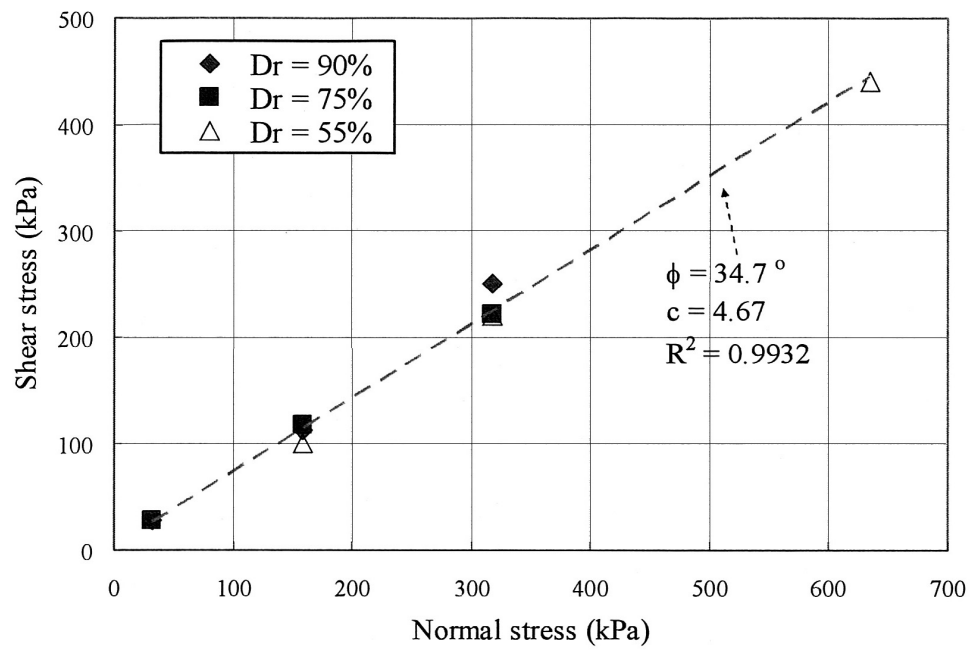

(b)

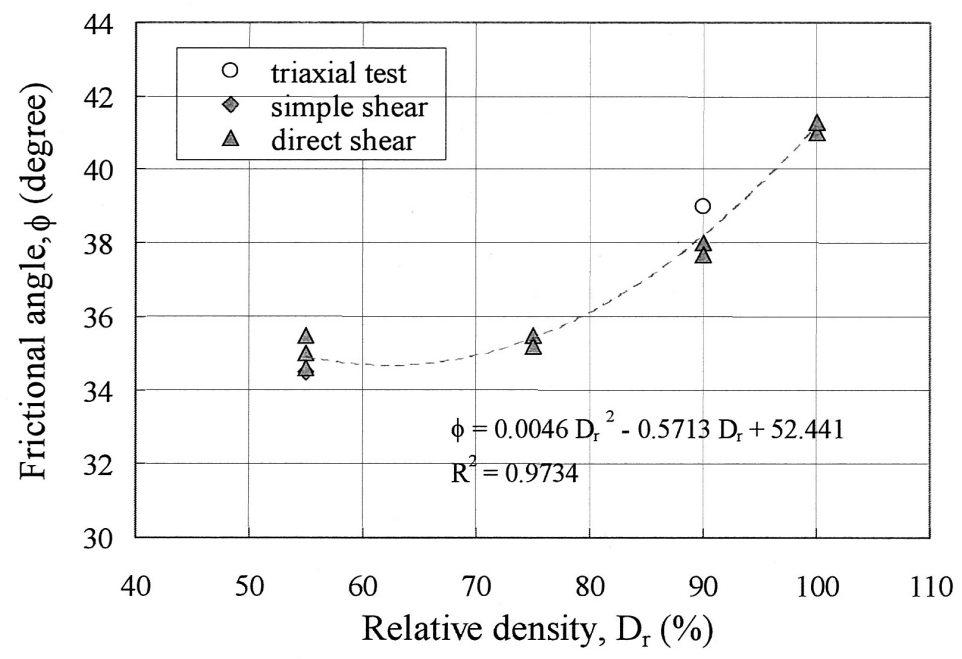

Fig. 3. Strength of sand obtained from tests.

(a) shear strength (envelope) obtained from direct shear test. The mean frictional angle is $34.7^{\circ}$, but it various from $34^{\circ}$ to $41^{\circ}$ with increasing $\mathrm{D}_{\mathrm{r}}$ as shown in Part (b).

(b) Variation of $\phi$ with $D_{r}$ obtained from different tests. 


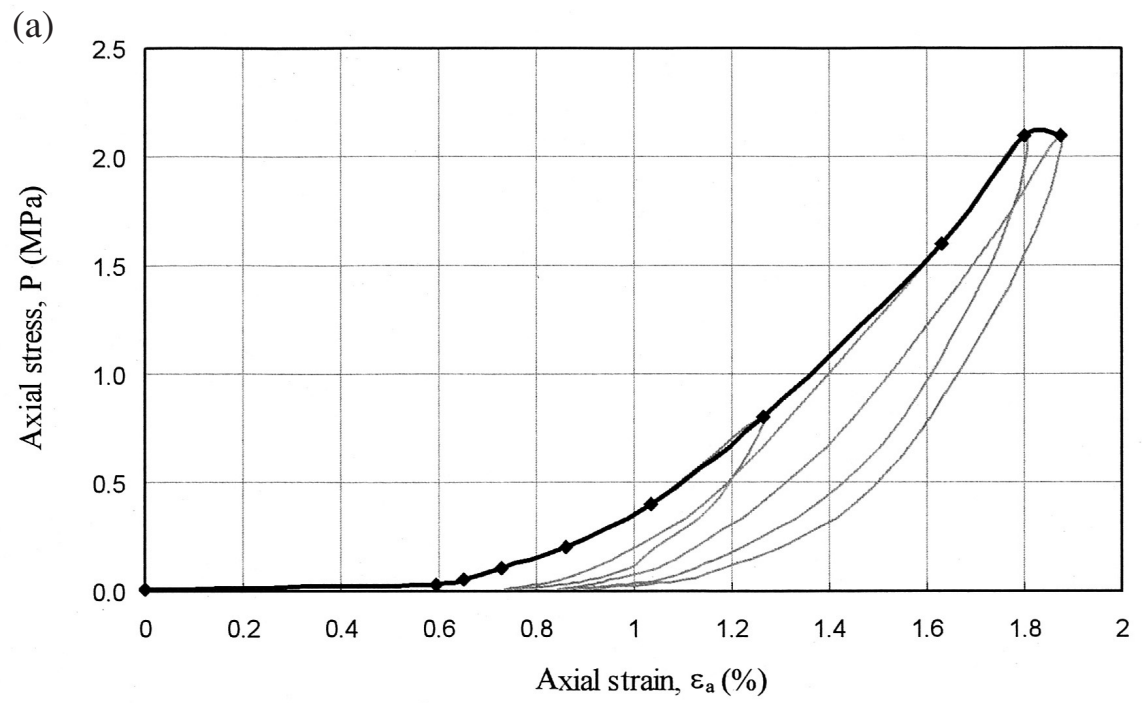

(b)

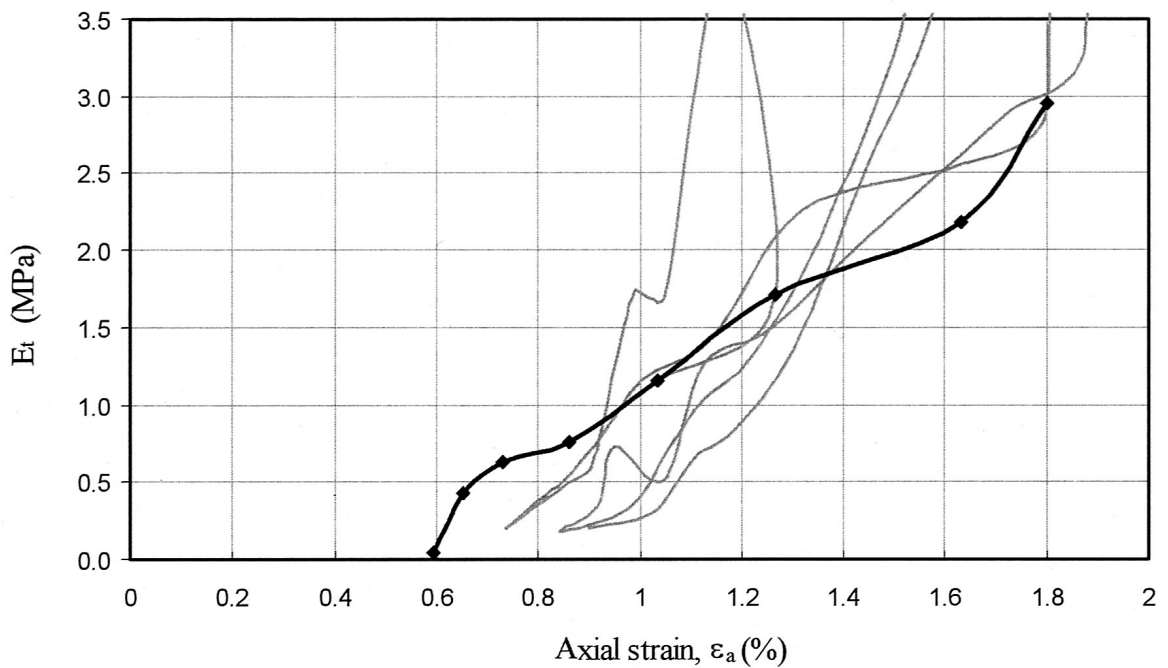

Fig. 4. Deformational behavior of sand obtained from uniaxial strain test (a) Axial stress versus axial strain.

(b) Tangent deformational modulus $\left(E_{t}\right)$ versus axial strain. 
(a)

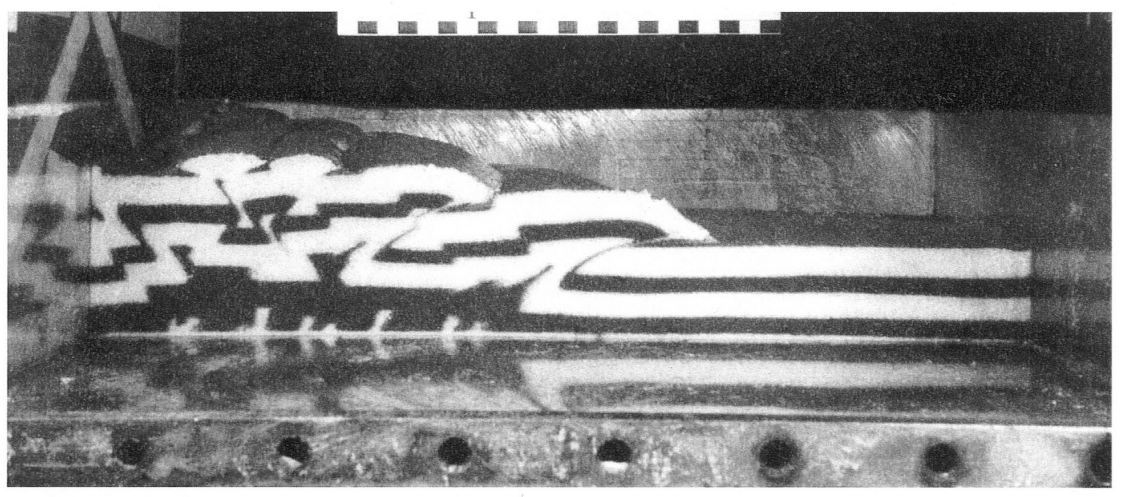

(b)

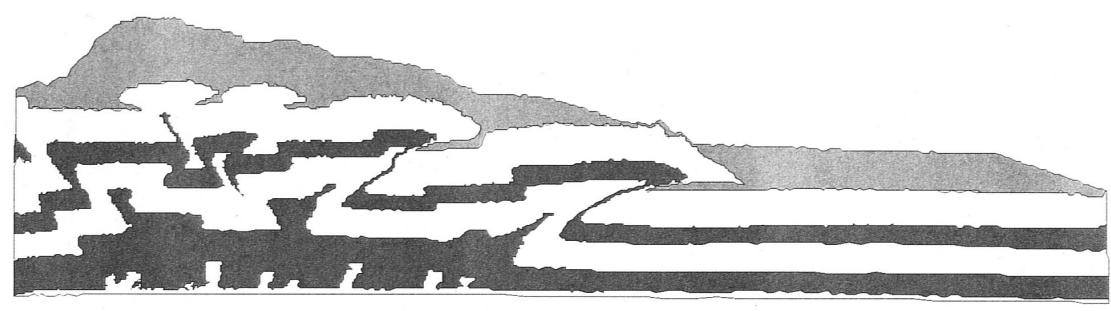

Fig. 5. Typical outcome of simulation obtained from sandbox experiments

(a) photo of simulated outcome.

(b) sketch of the photo.

ward rotation and was squeezed with greater thickening. Moreover, local thrust faults occurred on both sides of the pop-up as indicated in Fig. 6b. Eventually, a new pop-up appeared in front of the pop-up such that the fault front propagated towards the left side of the model (Fig. 6b). As long as convergence continued, fault propagation proceeded and yielded new pop-ups until the experiment was stopped (Fig. 6e).

Vertical backstop is adopted in this research for the sake of simplifying the problem to be analyzed. Inclined backstop should be used for the purposes of tectonic simulation. The major differences between the inclined and the vertical backstop for the formation of thrust-and-fold are the deform domain near the backstop, out of this domain there are almost no differences. Those differences are:

1. At the beginning of the convergence (e.g., a stage in Fig. 6) a major back thrust developed near the backstop. This back thrust creates a triangular zone between the backstop and fault, this triangular zone varied with the dip of the backstop. For example, if the incline backstop 


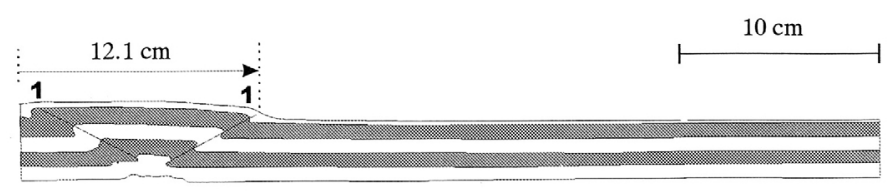

(a) pushing distance $=1 \mathrm{~cm}$

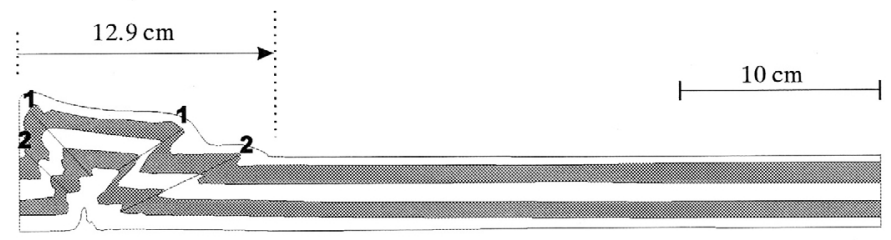

(b) pushing distance $=4 \mathrm{~cm}$

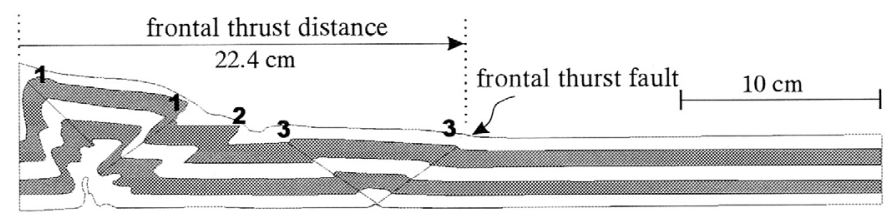

(c) pushing distance $=7 \mathrm{~cm}$

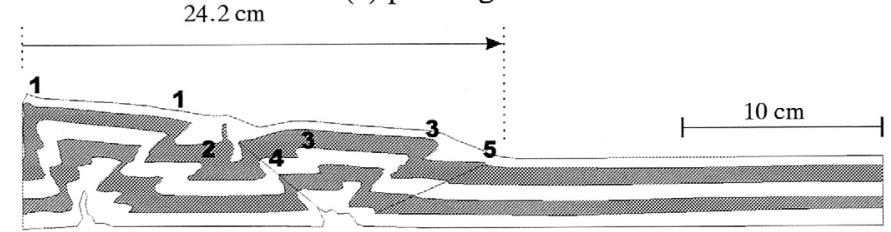

(d) pushing distance $=10.5 \mathrm{~cm}$

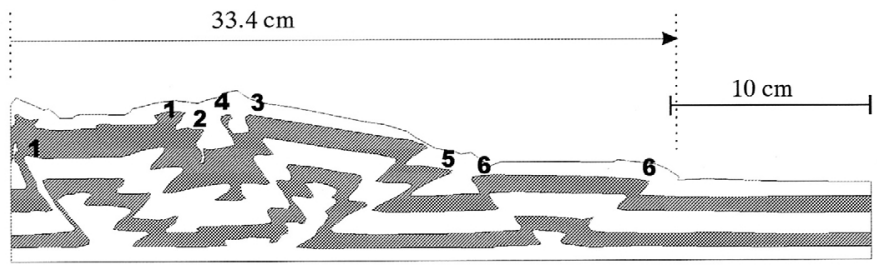

(e) pushing distance $=20 \mathrm{~cm}$

Fig. 6. Generation of thrust fault (thickness of sand $=4 \mathrm{~cm} ; 1 \mathrm{~g}$; Test No. 3 in Table 2). The numbers indicate the sequence of thrust fault generation. The length indicated by arrow is the distance of fault propagation.

(a) Distance of convergence $=0.5 \mathrm{~cm}$.

(b) Distance of convergence $=4 \mathrm{~cm}$.

(c) Distance of convergence $=7 \mathrm{~cm}$.

(d) Distance of convergence $=10.5 \mathrm{~cm}$.

(e) Distance of convergence $=20 \mathrm{~cm}$. 
has the same dip as back thrust (internal friction angle of sand) a major back thrust will develop on the surface of the backstop and no triangular zone exists.

2. During the later stages of the convergence this back thrust is addressed with greater dip angle, something that depends on the basal friction, and develops a disturbed zone after the tip of the back thrust reaches the wall of the backstop (e.g., stages b, c, d and e in Fig. 6).

Lohrmann et al. (2003), based on experiments under 1-g conditions, identified that the sequence of wedges formed by convergence can be categorized into three zones: the frontaldeformation zone (FDZ), the frontal-imbrication zone (FIZ) and the internal-accumulation zone (IAZ). Among these zones, the FIZ is the typical critical wedge, and can be well described by the corresponding theories. In this research, the results obtained in smaller depth scale are similar to that observed by Lohrmann et al. (2003). As the normal stress increases (the greater depth scale), piggy-back structures are gradually replaced by pop-up structures, which is similar to the observations by Mulugeta (1998).

\subsection{Scale Effect}

As model scales were altered, discrepancies arose in the internal deformation patterns even though convergence resulted in similar topography, faulting lineaments, thrust faults and pop-up structures being created (Fig. 7). When the thickness of sand is $2 \mathrm{~cm}$ and the convergence distance is $10 \mathrm{H}$, comparing Fig. 7a (normal gravity, $1 \mathrm{~g}$ ) and Fig. 7c $(20 \mathrm{~g})$, the model with a greater depth scale tends to have a longer frontal fault distance, and a smaller slope angle of the formed wedge in the frontal-deformation zone and the frontal-imbrication zone.

When the thickness of sand is $4 \mathrm{~cm}$, comparing Fig. 7b (normal gravity, $1 \mathrm{~g}$ ) and Fig. 7d $(20 \mathrm{~g})$, similarly, the model with a greater depth scale tends to have a longer frontal fault distance, and a smaller slope angle of the formed wedge in the frontal deformation zone and frontal-imbrication zone.

The scale difference also renders discrepancies in internal structures. A greater distance to the deformation front enables the deformation to be accommodated over a wider region. Consequently, the model with a greater depth scale has a lower concentration of deformation near the backstop and less thickening as well. This deformation pattern can be further depicted from the internal structures shown in Figs. 7a, b, in which the smaller depth scale model has a more severe deformation concentration in the internal-accumulation zone near the backstop.

For the case shown in Fig. 7d, which has the smallest relative convergence distance $(3.6 \mathrm{H})$, since the larger depth scale tends to have a greater front fault distance, the frontal-fault distance $(8 \mathrm{H})$ is already close to the case shown in Fig. $7 \mathrm{~b}(8.4 \mathrm{H})$, in which the convergence distance is $5 \mathrm{H}$.

In other words, a greater depth scale tends to create a narrow (shallow)-tapered wedge and a wider and more symmetric deformation zone and vise versa (Dahlen 1990). Based on the above-mentioned observations and the critical wedge theory, greater strength and smaller base friction facilitate the propagation of deformation. Under greater embedded stresses, owing to the greater thickness of soil, the sand is compacted and has greater strength, and internal frictional angle; however, basal friction may also increase (Acar et al. 1982). These two compensating phenomena may ease scale effect. However, scale effect is still significant, implying 
nonlinear increases in stiffness that distribute deformation to farther regions. This may play an important role accounting for scale effect.
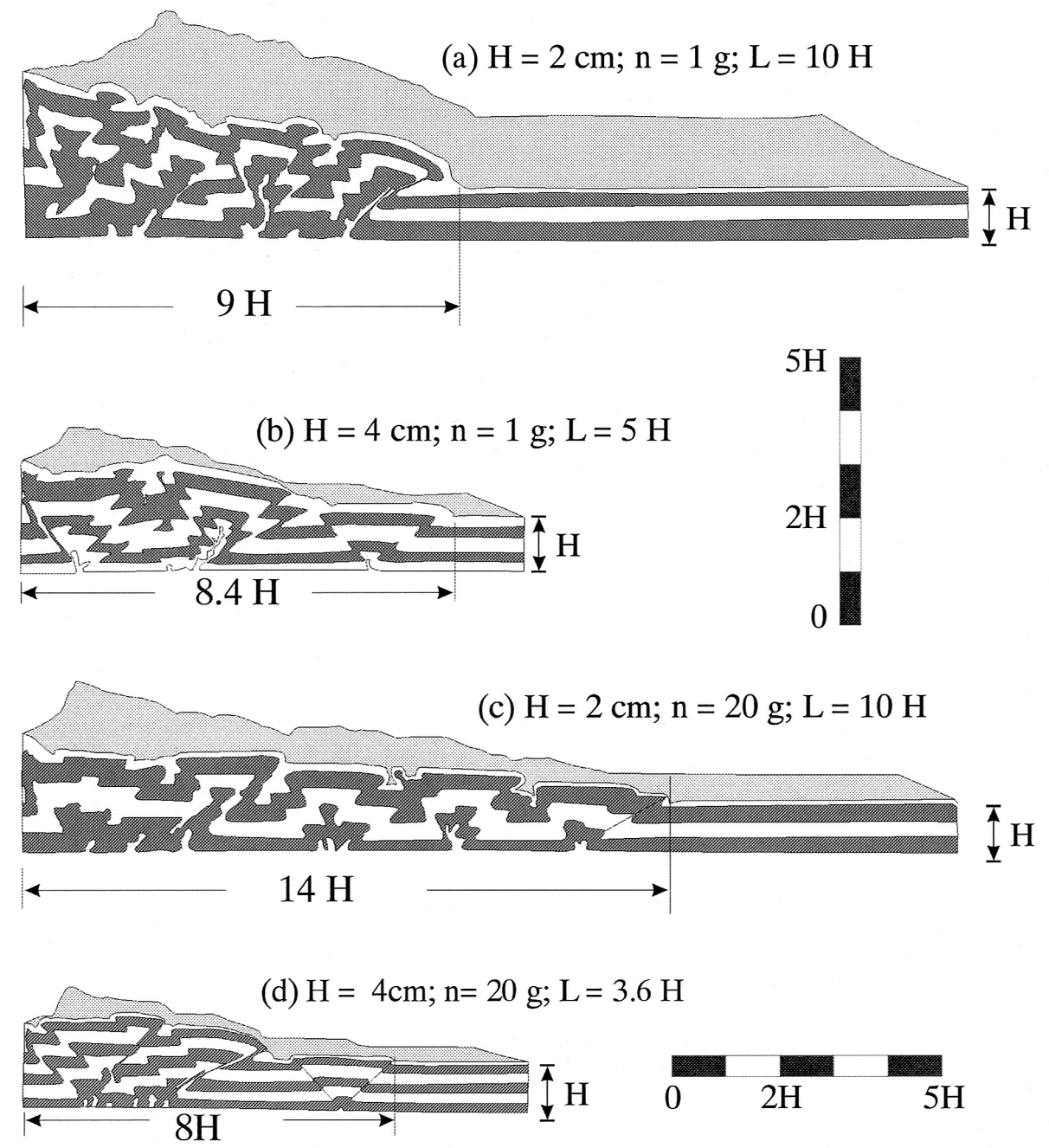

Fig. 7. Deformation patterns of various models. $H=$ thickness of sand; $n=$ magnitude of gravity; $L=$ distance of convergence.
(a) $\mathrm{H}=2 \mathrm{~cm} ; \mathrm{n}=1 \mathrm{~g} ; \mathrm{L}=10 \mathrm{H}$
(b) $\mathrm{H}=4 \mathrm{~cm} ; \mathrm{n}=1 \mathrm{~g} ; \mathrm{L}=5 \mathrm{H}$
(c) $\mathrm{H}=2 \mathrm{~cm} ; \mathrm{n}=20 \mathrm{~g} ; \mathrm{L}=10 \mathrm{H}$
(d) $\mathrm{H}=4 \mathrm{~cm} ; \mathrm{n}=20 \mathrm{~g} ; \mathrm{L}=3.6 \mathrm{H}$ 


\section{TEST RESULTS - MODELS WITH UNDER-LAIN BASEMENT HIGH}

In this test series, the plate convergence was stopped when the thrust fault front began to approach the Penghu Islands, since no tectonic thrust faults have been discovered beyond the Penghu Islands. For both $1 \mathrm{~g}$ and $20 \mathrm{~g}$ conditions, the overall forms of the thrust fault front are nearly the same when the fault fronts approach the Penghu Islands. However, the convergence distance in $1 \mathrm{~g}$ and $20 \mathrm{~g}$ tests are $14.5 \mathrm{~cm}$ and $13.5 \mathrm{~cm}$, respectively. In view of the scale effect, this finding is consistent with that observed from flat-base modeling. Namely, given the same distance of convergence, the model with a greater scale tends to distribute the deformation over a broader region. Or in a reverse situation, to have the same distance of fault front propagation, less convergence distance is required for the model with a greater scale.

\subsection{Topographical Features}

Figure 8 illustrates the topography yielded under $1 \mathrm{~g}$ and $20 \mathrm{~g}$ conditions, in which the thickness of sand varies from $2 \mathrm{~cm}$ to $0.1 \mathrm{~cm}$ from the non-elevated base to the elevated base. Based on the aforementioned observations, the greater scale $(20 \mathrm{~g})$ should render a greater distance for the frontal thrust fault under the same convergence distance; however, owing to the existence of the basement high, similar topologies were obtained for these two depth scales: three major fault groups are formed and the lineaments of the fault groups are curved in a similar pattern. These comparable features imply that the kinematic constraint (i.e., the existence of the basement) controls these features of simulation ( $\mathrm{Lu}$ et al. 1998).

Further observation (Fig. 8) reveals that the model under $20 \mathrm{~g}$ has a lower stacking height near the backstop and a greater distance between fault group 2 and group 3. Furthermore, a discrepancy in the formation of piggyback basins was observed. As most piggyback basins are created between fault group 2 and 3 in both scales, the wider distance of the fault groups in the $20 \mathrm{~g}$ model enables more piggyback basins (Fig. 9). Notably, the curved faulting lineaments become more curved when in proximity to or on the ascending slope of the basement high (Figs. 9a, b). Figure 9 schematically depicts the lineaments of the topographical features, in which the solid lines and the dashed lined represent the actual and the simulated fault lines, respectively. Here, the curved lineaments and the corresponding piggyback basins (indicated by shaded ellipses) reflect the influence of the embedded basement high. The dash-lined rectangle represents the range of the sandbox experiments and the locations of the profiles AA', BB', CC' and DD' of Fig. 10 are also indicated in Fig. 9.

In light of the above discussion, a question arises as to which simulation is more representative of the actual tectonic structure. As the model's configuration is preliminary and is constructed only for studying scale effect instead of simulating the actual tectonic process, deciding which scale is more representative may be inappropriate. Based on the simulation by $\mathrm{Lu}$ and Malavieille (1994), a sophisticated model should at least include an inclined backstop, a greater sandbox and a sufficient distance of convergence as well. Notably, a sophisticated simulation of the evolution of the western Taiwan fold-thrust belt should at least involve plate convergence, mountain building and growth of the foreland basin (Wang 2001; Mouthereau et al. 2002). It is not the intention of this research to simulate the evolution but to explore what 
(a)

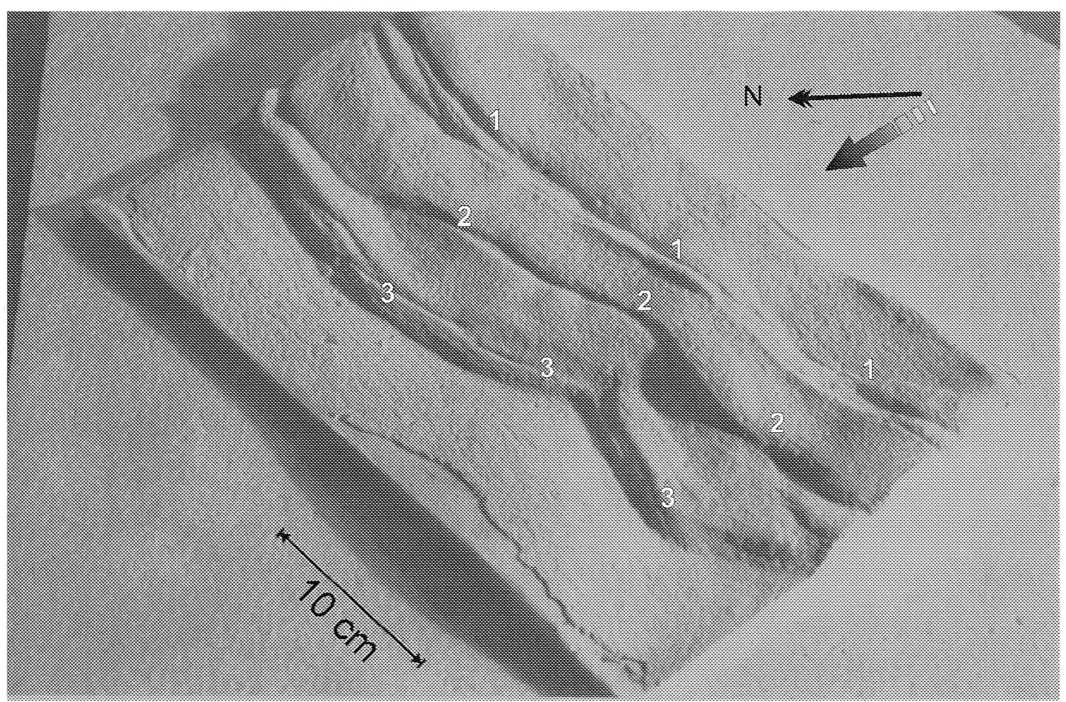

(b)

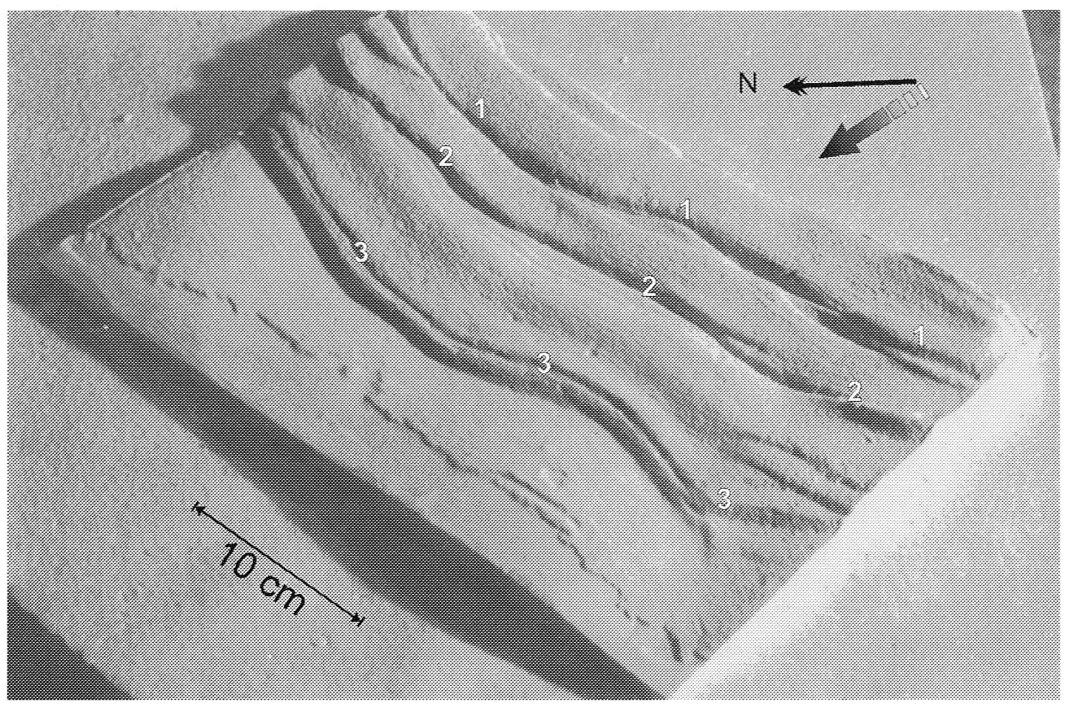

Fig. 8. Topography yielded under $1 \mathrm{~g}$ and $20 \mathrm{~g}$ conditions. The arrows indicate the direction of convergence. $\mathrm{L}_{\mathrm{f}}$ represents final distance of convergence. The major fault groups are indicated by the numbers.

(a) Topography yielded under $1 \mathrm{~g}$ condition $\left(\mathrm{L}_{\mathrm{f}}=14.5 \mathrm{~cm}\right)$

(b) Topography yielded under $20 \mathrm{~g}$ condition $\left(\mathrm{L}_{\mathrm{f}}=13.5 \mathrm{~cm}\right)$ 
may affect the outcome of simulation. As such, the outcomes of simulations tested under different depth scales are compared with the current structure of Taiwan, as shown in Fig. 9. Not surprisingly, discrepancies exist between the simulated and the actual structures for both model scales.

\subsection{Internal Structures}

Concerning scale effect on internal structures (e.g., the stacking height, the locations of the major fault groups, the number of piggyback basins), a comparison of such structures, profiles AA', BB', CC' and DD', of the two models is in shown Fig. 10. Here, although the final fault propagation distance is nearly identical, the model squeezed under normal gravity has

(a)

(b)
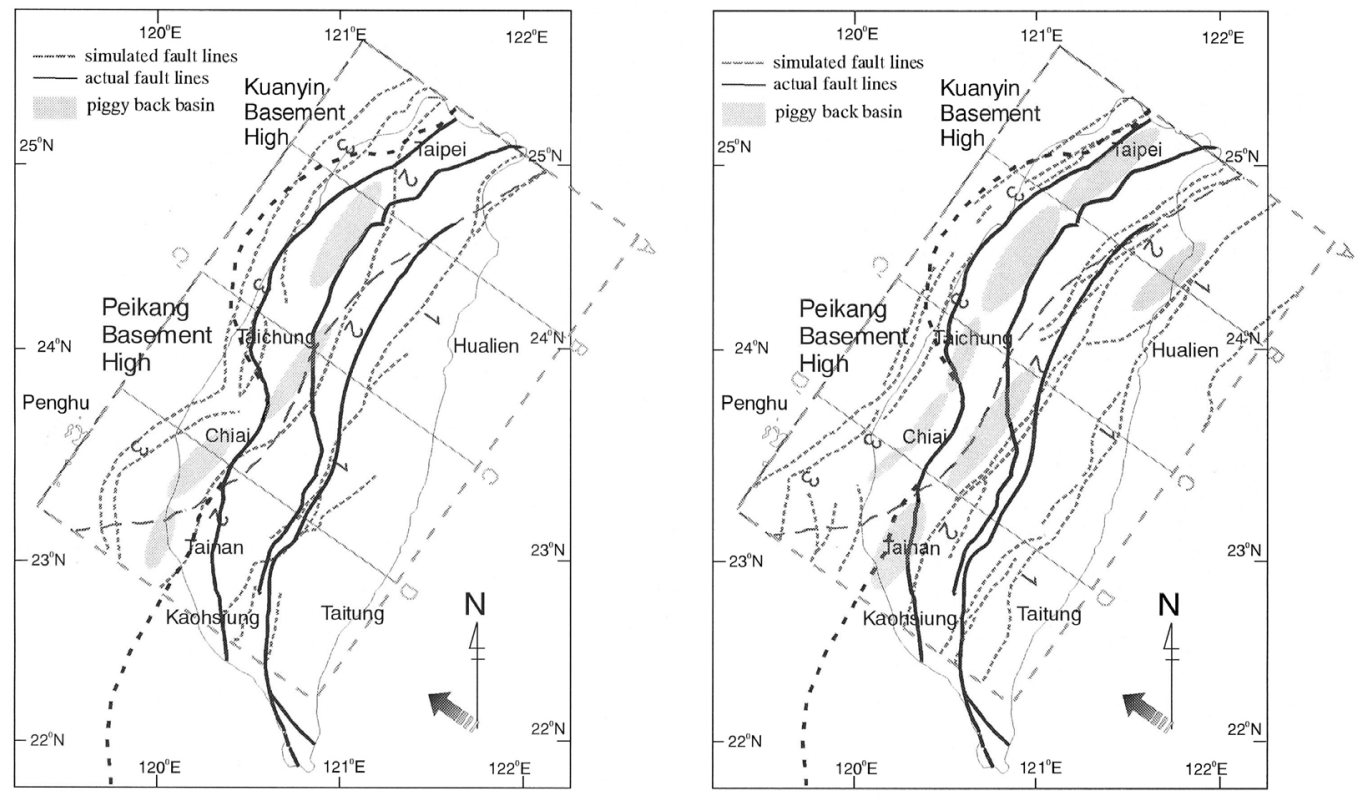

Fig. 9. Lineaments yielded under $1 \mathrm{~g}$ (a) and $20 \mathrm{~g}$ (b) conditions. The geometry of of the under-lain basement high is indicated by a shaded area. The numbers indicate the major thrust fault group. The direction of convergence is shown by the solid arrows. The location and size of piggyback basins are roughly denoted by the shaded ellipses. The profile of the cross-section AA', BB', CC' and DD' are shown in Fig. 10. The lineaments indicated in light color and in dark color are the experimental results and the actual faults, respectively. 
only one major pop-up structure and many back-thrusts on the ascending slope in a majority of the model. Meanwhile, the model squeezed under $20 \mathrm{~g}$ has two major, less deformed pop-ups in most cross-sections. In addition, the model under normal gravity has a more severe deformation concentration near the backstop such that more local thrusts developed near the major pop-up. This subsequently induces a greater thickening, more clockwise rotation of the wedge and, ultimately, a narrower spacing between thrust group 1 and 2 . These results correspond to those obtained from the flat-base model. Restated, the model with a smaller scale tends to have more severe deformation concentration near the backstop.

Remarkably, the many back thrusts prevailing over in the edges of the basement high, simulated under $1 \mathrm{~g}$ conditions (Fig. 10a), are not observed in the actual world. Too higher

(a)
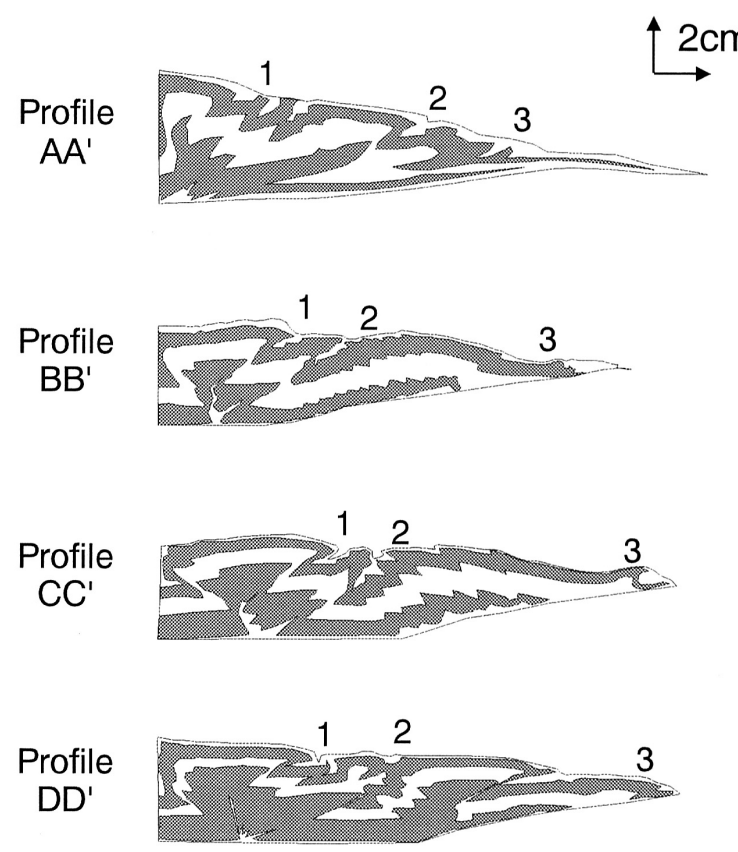

(b)
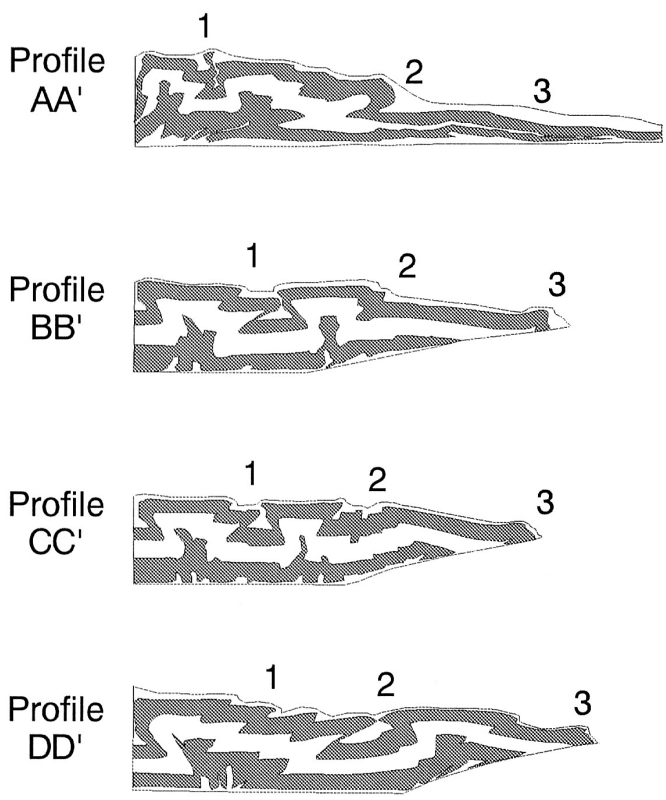

Fig. 10. Internal structures yielded under $1 \mathrm{~g}$ and $20 \mathrm{~g}$ conditions. The numbers indicate the sequence and location of major lineaments. The location of profiles is shown in Fig. 9.

(a) Structures yielded under $1 \mathrm{~g}$ condition.

(b) Structures yielded under $20 \mathrm{~g}$ condition. 
base friction along the basement high may account for so many back thrusts. Since the greater scale may compensate for the influence of base friction, a smaller number of back-thrust faults were formed under $20 \mathrm{~g}$ conditions. This fact partly supports the authors' assertion regarding too higher base friction.

Overall, the existence of the basement high apparently suppresses the propagation and the distance of the frontal thrust fault as well as ease the scale effect on the appearance of topology, which is characterized by the three major fault grounds and the curved lineaments. Nevertheless, scale effect on the internal structure still exists. Greater depth scale results in more pop-up structures and many fewer back-thrust faults, which is a result of basal friction being compensated.

Table 3 summarizes the influence of scale discrepancy on the topography or internal structures formed by plate convergence. In general, the outcomes to which the scale effect is not obvious include the number of major faults and curved faulting lineament, which is possibly controlled by kinematic constraints. However, when the kinematic constraint does not play a dominating role, scale effect exists in many features. Notable examples include the required convergence distance, location of faults and deformation concentration.

Table 3. Summary of scale effect.

\begin{tabular}{|l|l|}
\hline \multicolumn{1}{|c|}{ Major features } & Scale effect \\
\hline Sequence of thrust faulting & Insignificant \\
\hline Number of fault groups & Insignificant \\
\hline Curved lineament of faults & Insignificant \\
\hline Required distance of convergence & Significant \\
\hline Piggyback basin & Significant \\
\hline Distance of frontal fault & Significant \\
\hline Stacking height & Significant \\
\hline Deformation concentration & Significant \\
\hline Internal structures & Significant \\
\hline
\end{tabular}




\section{DISCUSSION OF SCALE FACTORS}

The direct consequence of conducting plate convergence under centrifugal conditions is that the magnitude of stress level is magnified from that of normal gravity. For instance, assuming the magnitude of gravity is $n$ times $g$, then the material in model located at a depth of $h$ is subject to a consolidation stress of $\rho \times n g \times h$, where $\rho$, denotes the density of sand. This magnitude of consolidation stress, $\rho \times n g \times h$, equals the stress in a depth of $n \times h$ in normal gravity. Consequently, the size of the model is magnified by $n$ times due to centrifugal force.

If the cohesive strength $\tau$ in Eqn. 1 is replaced by a more general term, the shear strength, as:

$$
\tau=c+\sigma_{n} \tan \phi
$$

where $\sigma_{n}$ is the normal stress, $\phi$ is the frictional angle and c represents the cohesive strength. If $c$ does not exist, the second term $\sigma_{n} \tan \phi$ alone would not cause any scale effect since it is proportional to the applied g-level. On the other hand, if $c$ does exist, then the dynamic similarity can be somewhat altered when changing the scale by applying different g-levels.

Despite strength, the stiffness of the material also plays an important role, especially in distributing stress during the convergence process. In fact, centrifugal force by inducing greater stress directly affects the material properties of sand, which vary with stress level, and this accounts for why sand inherently exhibits scale-dependent behavior, possibly contributing to scale effect in sandbox simulation. The scale-dependent properties of sand include stiffness, frictional angle and shear strength (Hubbert 1937; Hubbert 1951; Horsfield 1977; Krantz 1991; Schellart 2000; Lohrmann et al. 2003). An increase in applied stress results in the compaction of sand, which can be expressed in terms of increasing relative density or a decreasing void ratio. As the sand is compacted upon greater applied stress levels, the stiffness, strength and frictional angle of sand correspondingly increase. Figure $3 \mathrm{~b}$ depicts the variation of internal friction angle $(\phi)$ with the relative density. Therefore, an increase of the degree of compaction results in a combined effect of increasing stiffness (Fig. 4), frictional angle and sand strength.

In addition, if the model base is too rough, a sliding surface forms inside the sand instead of along the interface. Therefore, the interfacial friction angle between the sand and the model base is bounded by the internal frictional angle of sand. Namely, the interfacial friction may also depend on the internal friction and hence is potentially scale-dependent.

In addition to the understanding on when the critical wedge applies (Mulugeta 1998) and the influence of the non-linear failure envelope of sand on the outcome of sandbox experiments (Schellart 2000), this research further explored scale effect under low embedding stress level (scales 1 and 2) and high embedding stress (scales 10 and 20). In the latter (the high embedded stress) condition, the mechanism of scale effect seems to have been transformed from the material strength (cohesion and internal friction angle) to the stiffness of sand instead.

Therefore, understanding how sand compaction and base friction influence the simulation outcome is of relevant interest. Correspondingly, in this work, a third test series is conducted to investigate the impact of these two factors. Figure 11 summarizes a comparison of the experimental results. 


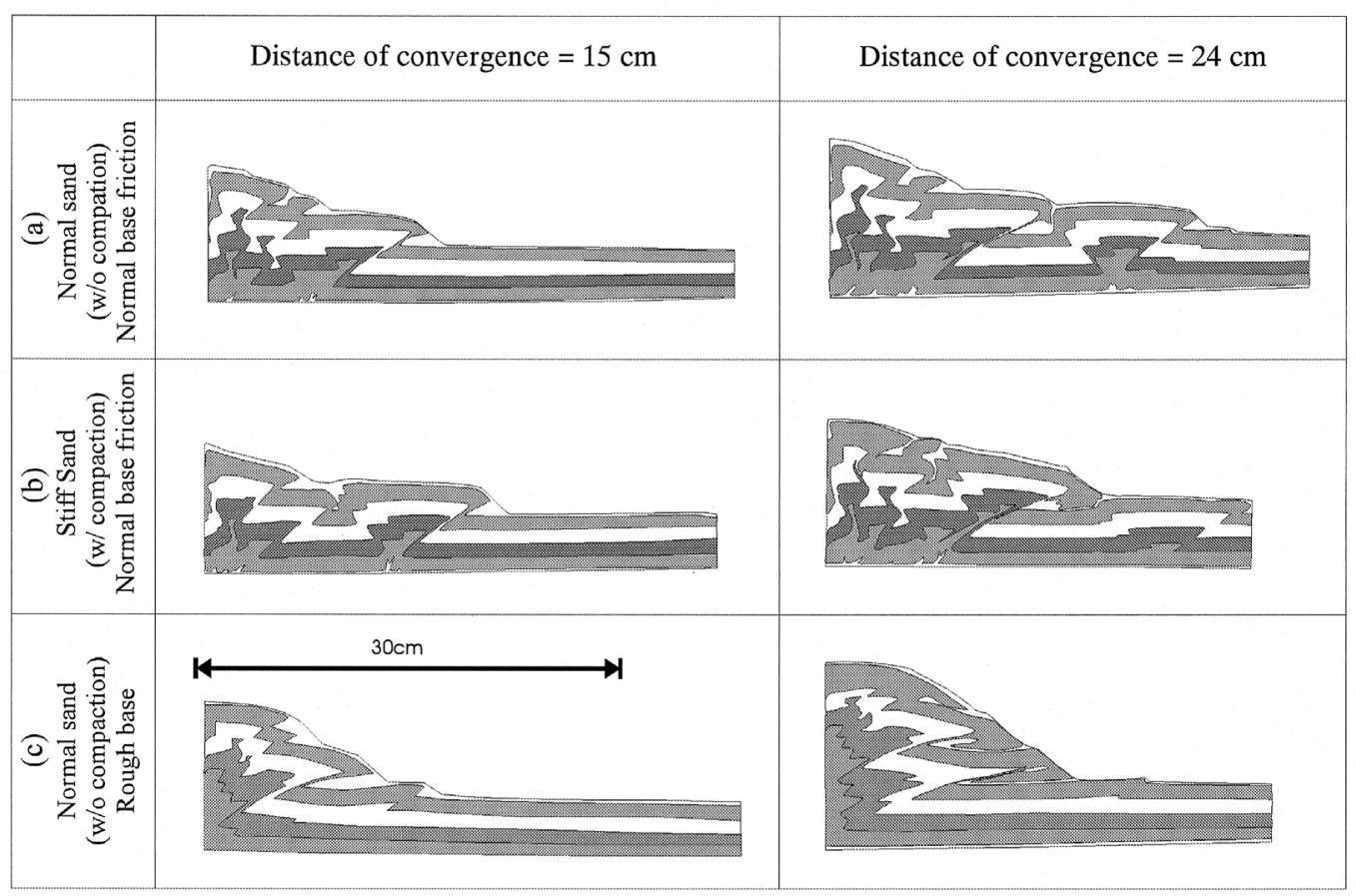

Fig. 11. Comparison of internal structures yielded under different conditions.

Figures $11 \mathrm{a}$ and $\mathrm{b}$ display the deformational patterns of un-compacted and compacted sand, respectively. According to these figures, it can be seen that the test of compacted sand results in a wider distribution of deformation characterized by a quicker occurrence of faults and a greater distance of fault propagation. This outcome closely resembles that obtained from a greater scale model.

This phenomenon can be explained as follows. As the sand is more compacted due to an increase of consolidation stress, the void ratio correspondingly decreases. Such a decrease implies that the grains are packed more closely, thereby enabling a better inter-locking and more grain-grain contacts. Consequently, the rolling of individual grains or severe local deformation is inhibited, reducing the local deformation concentration near the backstop. Meanwhile, the stress induced by the convergence can be distributed further towards the front.

Provided that the basal friction remains unchanged when increasing the g-levels, the farther distribution of thrust faulting (Figs. 7a, c; Figs. 11a, b) appears to be the result of sand compaction due to the weight of sand itself. Therefore, the compaction of sand is the prominent factor causing scale effect. However, since the compaction of sand represents an increase in stiffness, internal friction and strength, the influence of these sub-factors requires further investigation. 
In addition to compaction of sand, the basal friction may also contribute to scale effect. Figures 11a and c illustrate the deformation patterns of normal base friction and rough base, respectively. These figures reveal that, given the same convergence distance, the model with a rough base produces a more severe deformation concentration near the backstop, which is similar to model with a smaller scale. In other words, an increase in basal friction tends to create a steeper wedge and a more concentrated and asymmetric deformation zone and vise versa (Dahlen 1990).

Based on the aforementioned experimental results, a similar outcome can be obtained from models of different scales by altering the base friction. For instance, if a wider distribution of deformation is desired, a smoother base friction can be applied in a smaller scale model to yield a wider deformation distribution.

As mentioned earlier, the factors leading to scale effect include model geometry, boundary conditions, material properties, etc. Tests under $1 \mathrm{~g}$ conditions have the merits of being inexpensive and easy in setup and observation. However, if the basal friction prevents the desired longer distance of fault propagation, it is recommended that either a smooth base or more densely packed sand can be adopted to achieve the intended goal. Overall, since sand possesses non-linear stress and constitutive relations, which are similar to the behavior of soft rocks (Jeng et al. 1996, 2002; Weng et al. 2004) and may dominate the outcomes of simulations under various depth scales, these material properties should be cautiously controlled to enable a reasonable simulation and a common ground for comparison.

\section{CONCLUSIONS}

This study presents scale effect associated with the simulation of plate convergence, including topography, faulting lineaments and internal structures. Both scale dependent and scale independent phenomena have been observed. In addition, the possible factors causing scale effect are discussed and, to some extent, investigated. Results presented herein can hopefully provide a basis for determining a proper model scale and for further improving simulation techniques. Based on the results presented herein, we can conclude the following:

1. In the simulation of plate convergence using a sandbox, the simulation outcome can be scale dependent. Those scale dependent outcomes include the distance of fault propagation, required distance of convergence, distance between major faults, stacking heights and internal structures. However, as long as the kinematic constraint controls the outcomes, the outcomes (i.e., sequence of faulting, number of major fault groups and curved faults) can be compensated and can be, to some extent, scale independent;

2. Models at a smaller scale tend to have more localized deformation concentration near the backstop. Consequently, to yield the same distance of fault propagation, the smaller scale model requires a greater convergence distance;

3. Either an increase in compaction of sand or a decrease of interfacial friction enables a wider distribution of deformation. Of these two factors, the compaction of sand is the highlighted factor causing scale effect;

4. Correspondingly, with a proper adjustment of the following two factors, the dynamic simi- 
larity can still hold at different model scales: (a) to control base friction (e.g., by applying wax to the base or by increasing the roughness of base), or (b) to control the degree of compaction (e.g., by altering the relative density of sand); and

5. In the convergence simulation, some phenomena associated with folding, e.g., sliding along interfaces of layers and a variation of folding amplitude, are not clearly observed. Herein, the use of homogenous sand, instead of strata with different properties and viscosity, may directly prevent these phenomena from occurring. Regarding more realistic folding simulation during plate convergence, a more sophisticated model must be adopted, having layers of sand with different mechanical properties and adequate control of the interlayer friction.

Acknowledgments The author would like to thank the National Science Council of Taiwan for partially supporting this research under Contract No. NSC 87-2116-M002-003. Centrifuge experiments were performed at the centrifuge facility at the Department of Civil Engineering, National Central University. The review comments provides by Prof. W. H. Wang, Dr. M-A Gutscher and an anonymous reviewer have significantly improved the scientific soundness of this paper and are gratefully acknowledged.

\section{REFERENCES}

Acar, Y. B., H. T. Durgunogle, and M. T. Tumay, 1982: Interface properties of sand.J. Geotech. Eng. Div. ASCE, 108, 648-654.

Barr, T. D., F. A. Dahlen, 1989: Brittle frictional mountain building 2. Thermal structure and heat budget. J. Geophys. Res., 94, 3923-3947.

Bonini, M., D. Sokoutis, G. Mulugeta, and E. Katrivanos, 2000: Modelling hanging wall accommodation above rigid thrust ramps. J. Struct. Geol., 22, 1165-1179.

Byrne, D. E., W. H. Wang, and D. M. Davis, 1993: Mechanical role of backstops in the growth of forearcs. Tectonics, 12, 123-144.

Calassou, S., C. Larroque, and J. Malavieille,1993: Transfer zones of deformation in thrust wedges: an experimental study. Tectonophys., 221, 325-344.

Colletta, B., J. Letouzey, R. Pinedo, J. F. Ballard, and P. Balé, 1991: Computerized X-ray tomography analysis of sandbox models: Examples of thin-skinned thrust systems. Geol., 19, 1063-1067.

Costa, E., and B. C. Vendeville, 2002: Experimental insights on the geometry and kinematics of fold-and-thrust belts above weak, viscous evaporitic decollement. J. Struct. Geol., 24, 1729-1739.

Couzens-Schultz, B. A., B. C. Vendeville, and D. V. Wiltschko, 2003: Duplex style and triangle zone formation: insights from physical modeling. J. Struct. Geol., 25, 1623-1644.

Dahlen, F. A., 1990., Critical taper model of fold-and thrust belts and accretionary wedges. Ann. Rev. Earth Planet. Sci., 18, 55-99.

Dahlen, F. A., and T. D. Barr, 1989: Brittle frictional mountain building 1. Deformation and mechanical energy budget. J. Geophys. Res., 94, 3906-3922.

Dahlen, F. A., J. Suppe, and D. Davis, 1984: Mechanics of fold and-thrust belts and accretionary wedges: cohesive coulomb theory.J. Geophys. Res., 89, 10087-10101. 
Davis, D., J. Suppe, and F. A. Dahlen, 1983: Mechanics of fold and thrust belts and accretionary wedges. J. Geophys. Res., 88, 1153-1172.

Gutscher, M. A., N. Kukowski, J. Malavieille, and S. Lallemand, 1996: Cyclical behavior of thrust wedges: Insights from high basal friction sandbox experiments. Geology, 24, 135-138.

Gutscher, M. A., N. Kukowski, J. Malavieille, S. E. Lallemand, 1998a: Material transfer in accretionary wedges from analysis of a systematic series of analog experiments. $J$. Struct. Geol., 20, 407-416.

Gutscher, M. A., N. Kukowski, J. Malavieille, and S. E. Lallemand, 1998b: Episodic imbricate thrusting and underthrusting: analog experiments and mechanical analysis applied to the Alaskan accretionary wedge. J. Geophys. Res., 103, 10161- 10176.

Horsfield, W. T., 1977: An experimental approach to basement controlled faulting. Geologie Mijub., 56, 363-370.

Hubbert, M. K., 1937: Theory of the scale models as applied to the study of geologic structures. Geol. Soc. Am. Bull., 48, 1459-1520.

Hubbert, M. K., 1951: Mechanical basis for certain familiar geologic structures. Geol. Soc. Am. Bull., 62, 335-372.

Jeng, F. S., M. H. Hsiao, and C. Y. Lu, 1996: Numerical simulation of neotectonics near Peikang High. J. Geol. Soc. China, 39, 557-578.

Jeng, F. S., W. C. Weng, T. H. Huang, and M. L. Lin, 2002: Deformational Characteristics of Weak Sandstone and Impact to Tunnel Deformation. Tunnel. Undergr. Space, 17, 263264.

Koyi, H. A., 1955: Mode of internal deformation in sand wedges. J. Struct. Geol., 17, 293300.

Koyi, H. A., and B. C. Vendeville, 2003: The effect of deécollement dip on geometry and kinematics of model accretionary wedges. J. Struct. Geol., 25, 1445-1450.

Krantz, R.W., 1991: Measurements of friction coefficients and cohesion for faulting and fault reactivation in laboratory models, using sand and sand mixtures. Tectonophys., $\mathbf{1 8 8}$, 203-207.

Lallemand, S. E., J. Malavieille, and S. Calassou, 1992: Effects of oceanic ridge subduction on accretionary wedges: experimental Modeling and marine observations.Tectonics, 11, 1301- 1313.

Lallemand, S. E., P. Schnurle, J. Malavieille, 1994: Coulomb theory applied to accretionary and non-accretionary wedges: possible causes for tectonic erosion and/or frontal accretion. J. Geophys. Res., 99, 12033-12055.

Liu, H., K. R. McClay, and D. Powell, 1991: Physical models of thrust wedges. In: K. R. McClay (Ed.), Thrust Tectonics. Chapman \& Hall, 71-80.

Liu, S., and J. M. Dixon, 1991: Centrifuge modelling of thrust faulting: structural variation along strike in fold-thrust belts. Tectonophys., 188, 39-62.

Lohrmann, Jo, N. Kukowski, J. Adam, and O. Oncken, 2003: The impact of analogue material properties on the geometry, kinematics, and dynamics of convergent sand wedges. J. Struct. Geol., 25, 1691-1711. 
Lu, C. Y., J. Angelier, H. T. Chu, and J. C. Lee, 1995: Contractional, transcurrent, rotational and extensional tectonics: Examples from northern Taiwan. Tectonophys., 246, 129 146.

Lu, C. Y., F. S. Jeng, K. J. Chang, and W. T. Jian, 1998: Impact of basement high on the structure and kinematics of the western Taiwan thrust wedge: Insights from sandbox models. Terr. Atmos. Ocean. Sci., 9, 533-550.

Lu, C. Y., and J. Malavieille, 1994: Oblique convergence, indentation and rotation tectonic in the Taiwan mountain belt: insights from experimental modeling. Earth Planet. Sci. Lett., 121, 477-494.

Lu, C. Y. , H. T. Chu, J. C. Lee, Y. C. Chan, K. J. Chang, and F. Moutherau, 2002: The 1999 Chi-Chi Taiwan earthquake and basement impact thrust kinematics. West. Pac. Earth Sci., 2, 181-190.

Maillard, A, V. Gaullier, B. C. Vendeville, and F. Odonne, 2003: Influence of differential compaction above basement steps on salt tectonics in the Ligurian-Provencal Basin, northwest Mediterranean. Mar. Petroleum Geol., 20, 13-27

Malavieille, J., 1984: Modélisation experimentale des chevauchements imbriqués: application aux chaines de montagnes. Bull. Soc. Géol. France, 26, 129-138.

Mouthereau, F., B. Deffontaines, O. Lacombe, and J. Angelier, 2002: Along-strike variations of the Taiwan belt front: Basement control on structural style, wedge geometry and kinematics. Spec. Pub. Geol. Soc. Am., 358, 35-58.

Mugnier, J. L., P. Baby, B. Colletta, P. Vinour, P. Bale, and P. Leturmy, 1997: Thrust geometry controlled by erosion and sedimentation: a view from analogue models. Geology, 25, 427- 430 .

Mulugeta, G., 1988a: Modelling of the geometry of the Coulomb thrust wedges. J. Struct. Geol., 10, 847-859.

Mulugeta, G., 1988b: Squeeze box in a centrifuge. Tectonophys., 148, 323-335.

Mulugeta, G., 2002: Scale effects and rheologic constraints in ramp-flat thrust models. In: Schellart, W. P., and C. Passchier (Eds.), Analogue Modelling of Large-scale Tectonic Processes. J. Virtual Explorer, 7, 51-50.

Sassi, W., B. Colletta, P. Bale, and T. Paquereau, 1993: Modeling of structural complexity in sedimentary basin: the role of pre- existing faults in thrust tectonics. Tectonophys., 226, 97-112.

Schellart, W. P., 2002: Analogue modelling of large-scale tectonic processes: an introduction. In: Schellart, W. P., and C. W. Passchier (Eds.), Analogue modelling of large-scale tectonic processes. J. Virtual Explorer, 7, 1-6.

Storti, F., F. Salvini, and K. McClay, 1997: Fault- related folding in sandbox analogue models of thrust wedges. J. Struct. Geol., 19, 583- 602.

Suppe, J., 1980: A retrodeformable Cross section of northern Taiwan.Proc. Geol. Soc. China, 23, 46-55.

Suppe, J., 1980: Imbricated structure of western foothills belt, south- central Taiwan. Petro. Geol. Taiwan, 17, 1- 16.

Suppe, J., 1981: Mechanics of mountain building and metamorphism in Taiwan.Mem. Geol. Soc. China, 4, 67-89. 
Suppe, J., 1983: Geometry and kinematics of fault-bend folding. Am. J. Sci., 283, 684-721.

Wang, W. H., 2001: Lithosphere flexure under a critically tapered mountain belt: a new technique to study the evolution of the Tertiary Taiwan orogeny. Earth Planet. Sci. Lett., 192, 571-581.

Wang, W. H., and W. J. Hung, 2002: Synorogenic extension, Taiwan: Implications of physical and numerical modeling. Geol. Soc. Am. Bull., 538, 137-146.

Weng, M. C., F. S. Jeng, T. H. Huang, and M. L. Lin, 2004: Characterizing the deformation behavior of Tertiary sandstones. Inter. J. Rock Mech. Mining Sci., 42, 388-401.

Willett, S., 1992: Dynamic and kinematic growth and change of a Coulomb wedge. In: K. R. McClay (Ed.), Thrust Tectonics, 19-31.

Willett, S., C. Beaumont, and P. Fullsack,1993: Mechanical model for the tectonics of doubly vergent compressional orogens. Geology, 21, 371-374. 